\title{
Intersubjetivismo versus subjetivismo? Algumas considerações sobre a controvérsia Habermas-Henrich a partir das "Doze teses contra Jürgen Habermas"*
}

\author{
Fernando Costa Mattos \\ Doutor em filosofia pela USP, desenvolve atualmente \\ pesquisa de pós-doutoramento, com bolsa da FAPESP, \\ junto ao Núcleo Direito e Democracia do CEBRAP
}

Do ponto de vista bibliográfico, a relação entre Jürgen Habermas e Dieter Henrich pode ser retraçada até 1974, ano de publicação do opúsculo Zwei Reden (Duas conferências). ${ }^{1}$ Encontram-se nele as falas proferidas por ambos quando da entrega, em janeiro de 1974, de um prêmio oferecido a Habermas pela cidade de Stuttgart - o Hegel-Preis de 1973. Responsável pela laudatio ao homenageado, Henrich faz uma espécie de balanço da trajetória do ainda jovem intelectual (aos 44, Habermas estava a sete anos de publicar a Teoria do agir comunicativo) e, à parte os acalorados elogios - o homenageado só perderia em importância, no cenário alemão contemporâneo, para ninguém menos do que Martin Heidegger ${ }^{2}-$, Henrich observa na reflexão filosófica sobre

* "O que é metafísica? O que é modernidade? Doze teses contra Jürgen Habermas", traduzido por mim do original alemão "Was ist Metaphysik? - was Moderne? Zwölf Thesen gegen Jürgen Habermas” (In: Henrich, D. Konzepte. Essays zur Philosophie in der Zeit. Frankfurt-am-Main: Suhrkamp, 1988) e publicado a seguir, na seção de traduções deste número dos Cadernos de Filosofia Alemã.

1. Uma boa reconstrução do debate entre os dois autores pode ser encontrada em Heider, P. Jürgen Habermas und Dieter Henrich. Neue Perspektiven auf Identität und Wirklichkeit. Freiburg, München: Alber, 1999, pp. 29-37. Também Antônio Martins desenvolve uma interessante análise sobre o tema na apresentação à tradução portuguesa do Pensamento pós-metafísico, livro em que Habermas publicaria, juntamente com outros textos, seus dois artigos contra Henrich: Habermas, J. Pensamento pós-metafísico. Tradução de Lumir Nahodil. Coimbra: Almedina, 2004.

2. Habermas, J.; Henrich, D. Zwei Reden. Aus Anlass des Hegel-Preises. Frankfurt-am-Main: Suhrkamp, 1974, p. 22. 
a linguagem, de um lado, e na análise sociológica das complexidades modernas, de outro, as principais características e virtudes de Habermas. ${ }^{3} \mathrm{O}$ que não the daria ainda, contudo, a marca da originalidade teórica: submetido desde o princípio, segundo Henrich, à influência da "antropologia de seu mestre [Erich Rothacker]", ele estaria "somente agora, depois de um longo caminho, iniciando uma teoria própria". ${ }^{4}$

Sem levar em conta, naturalmente, a nada lisonjeira observação de seu homenageante, Habermas ocupa-se em sua conferência da questão-título "Podem as sociedades complexas desenvolver uma identidade racional?". Tendo por base, como sempre, os diagnósticos sociológicos que desde Weber apontam para uma crise da racionalidade nas complexas sociedades modernas, Habermas trata de discutir nesse texto o quanto isso teria inviabilizado a formação de uma identidade coletiva racional no sentido que este termo tinha na tradição, muito particularmente na filosofia hegeliana. ${ }^{5}$ É numa menção a Hegel, por sinal, que Habermas se refere pela única vez a Henrich, chamando o seu testemunho de comentador para atestar o elemento totalizante que, na obra do filósofo, permitiria conciliar necessidade e li-

3. Idem, pp. 20-1.

4. Idem, p. 21. Nas "Doze teses" - já, portanto, depois da publicação de Teoria do agir comunicativo e Discurso filosófico da modernidade - Henrich insistirá, curiosamente, nesse argumento de que Habermas não se teria libertado da influência de seu "primeiro mestre", Erich Rothacker. Rothacker foi orientador de Habermas em Bonn, durante o doutoramento sobre Schelling que este concluiu em 1954. Tendo-se ocupado, no plano teórico, sobretudo com a "antropologia cultural" e a "filosofia da vida", Rothacker é mais conhecido, no entanto, por ter colaborado ativamente com o regime nazista. Como chefe de uma divisão do Ministério da Propaganda, foi um dos principais responsáveis pela queima de livros de 1933. Em 1934, escreveu um livro sobre filosofia da história (Geschichtsphilosophie) em que defende a teoria racista do nacional-socialismo. Durante a Segunda Guerra Mundial, participou do projeto nazista "Kriegseinsatz der Geisteswissenschaften" ("Princípio de guerra das ciências do espírito"). Com o fim da guerra, perdeu suas funções, mas já em 1947 retomou a carreira docente na Universidade de Bonn e lá permaneceu até 1956, ano em que se tornaria Professor Emérito. Cf. verbete "Erich Rothacker", in: www.de.wikipedia.org.

5. Habermas, J.; Henrich, D. Zwei Reden. Aus Anlass des Hegel-Preises, p. 25. 
berdade (contingência). ${ }^{6}$ Como que antecipando, consciente ou inconscientemente, um dos pontos cruciais da futura polêmica, Habermas se vale desse comentário para afirmar a incompatibilidade da metafísica com as sociedades modernas, onde o acúmulo de "outras contingências" inviabilizaria, em princípio, a formação de um pensamento identitário do todo social. ${ }^{7}$

Embora não possa negar, face às transformações por que passaram as sociedades capitalistas nos últimos duzentos anos, a imensa dificuldade envolvida na tarefa de pensar hoje um sentido "totalizante" para o mundo, a aposta de Henrich é contrária à de Habermas: em seu livro Fluchtlinien (Linhas de fuga), escrito em $1981,{ }^{8}$ ele dirá que o caminho para enfrentar essa dificuldade está não no abandono, mas, muito pelo contrário, no revigoramento da metafísica moderna, cuja "compatibilidade" com as sociedades atuais estaria enraizada em nossa própria natureza humana subjetiva. ${ }^{9}$ Afinal, por mais que as pesquisas empíricas tenham apontado descritivamente, no correr do século XX, para a originariedade cronológica da intersubjetividade relativamente à subjetividade, isso não teria tirado a esta a sua função lógico-filosófica de locus mental onde o indivíduo humano capaz de pensar e falar - aquele, portanto, que em seu desenvolvimento cognitivo já se

6. Idem, p. 48. Cf. idem, pp. 78-9.

7. Idem, p. 48.

8. Henrich, D. Fluchtlinien. Philosophische Essays. Frankfurt-am-Main: Suhrkamp, 1982. Este livro foi o primeiro em que Henrich, até então tido "apenas" como um dos mais respeitados estudiosos de Kant e do idealismo alemão, se lançou à filosofia propriamente dita. Como observaria o próprio Habermas na resenha ao livro, "o autor fala pela primeira vez em seu próprio nome”. Habermas, J. Nachmetaphysisches Denken. Philosophische Aufsätze. Frankfurt-am-Main: Suhrkamp, 1988, p. 272. Além da já mencionada edição portuguesa, esse livro também foi traduzido para o português como: Habermas, J. Pensamento pós-metafísico. Tradução de Flávio B. Siebeneichler. Rio de Janeiro: Tempo Brasileiro, 2002 (2a . ed.).

9. Veja-se a descrição que faz Henrich da filosofia, logo na frase de abertura ao livro: "Todo homem filosofa. $\mathrm{E}$ as questões que o impulsionam a esse pensamento, que ele mal consegue colocar em palavras, dá à tradição do pensamento explícito fundado pelos gregos o seu direito de existência e a sua dignidade."Henrich, D. Fluchtlinien. Philosophische Essays, p. 7. 
percebe distinto da mãe ${ }^{10}$ - identifica aquilo que seria o seu "eu" e, para falar nos conhecidos termos de Kant, as representações que o acompanham. ${ }^{11}$

Descabendo aprofundarmo-nos por ora nesse texto de Henrich, cujos argumentos retomaremos adiante, essa brevíssima descrição de sua posição teórica terá bastado para produzir escândalo em qualquer defensor da teoria crítica. E permite imaginar desde logo o teor da reação habermasiana, manifesta numa resenha de 1985, publicada na revista Merkur sob o título "Rückkehr zur Metaphysik: Eine Tendez in der deutschen Philosophie?" "Retorno à metafísica: uma tendência na filosofia alemã?"). ${ }^{12}$ Como falar ainda em "natureza humana"?! Em "subjetividade"?! "Locus mental”?! "Indivíduo humano"?! "Representações que acompanham o eu”?!... É como se Dieter Henrich ignorasse, dirá Habermas nesse texto, tudo o que se passou na filosofia desde Hegel: numa atitude que faz lembrar um Jaspers mais metafísico do que o próprio admitiria, ${ }^{13}$ os esforços de Henrich, juntamente com os demais defensores da

10. Como é sabido, Habermas se vale fortemente da teoria do desenvolvimento cognitivo de Piaget, aliada às análises de Mead a respeito da formação da identidade subjetiva a partir da relação com o outro, para dar sustentação à crítica da filosofia do sujeito. Para Henrich, é fundamental distinguir esse ângulo psico-sociológico, empírico, do ponto de vista lógico-filosófico, de modo a impedir a redução deste àquele. Cf. idem, pp. 134-51. Quanto à importância de Mead para o modo como Habermas pretende superar a filosofia do sujeito, cf. Henrich, Daniel. Zwischen Bewusstseinsphilosophie und Naturalismus. Zu den metaphysischen Implikationen der Diskursethik von Jürgen Habermas. Bielefeld: Transcript Verlag, 2007, pp. 50-5.

11. Cf. Henrich, D. Fluchtlinien. Philosophische Essays, pp. 134-51.

12. Sob o título "Rückkehr zur Metaphysik? Eine Sammelrezension", o texto foi republicado, como apêndice, no já livro: Habermas, J. Nachmetaphysisches Denken. Frankfurt-am-Main: Suhrkamp, 1988, onde Habermas incluiria também a sua resposta às "Doze teses" de Henrich, à qual voltaremos adiante.

13. "Henrich fala de uma 'análise desveladora de formas de vida'. Isso lembra Jaspers. Este, porém, havia compreendido o deciframento do 'envolvente' como um negócio pós-metafísico. Também ele havia desacoplado a autocompreensão filosófica da pesquisa e da ciência objetivante, mas de tal modo que dela não se exigisse ter de exceder a pretensão teórica das ciências. (...) Mas Henrich se coloca a paradoxal tarefa de permanecer nas condições da consciência moderna e, ao mesmo tempo, justificar a iluminação filo- 
Rückkehr ${ }^{14}$ não passariam de uma tentativa desesperada $e$ extemporânea de salvar para a filosofia "os direitos inatos de um autoesclarecimento metafísico da vida consciente”. ${ }^{15}$

Os motivos especulativos que Henrich por boas razões gostaria de salvar determinam de fato o destino da filosofia. Para poder convencer, porém, eles têm de ser validados na ciência ou em conexão com ela. De nada adianta: filosoficamente, nós continuamos sendo contemporâneos dos jovens hegelianos. Desde então, a filosofia busca passar a outro meio: Karl-Otto Apel fala de uma 'transformação'. O título de um livro organizado por Thomas McCarthy é emblemático dessa situação: After Philosophy. O volume fornece um panorama dos princípios mais sérios de um pensamento pós-metafísico nos Estados Unidos e na Europa: de Davidson a Putnam e McIntyre, de Gadamer a Ricoeur e Apel. ${ }^{16}$

sófica como metafísica, como uma forma de teoria que supera as ciências.” Habermas, J. Nachmetaphysisches Denken, pp. 273-4.

14. Além de Henrich, Habermas tem em vista, nesse contexto, autores como Rüdiger Bubner, Robert Spaemann, Reinhard Löw e Michael Theunissen. Num contexto mais recente, poderíamos mencionar, entre outros, os seguintes autores, todos eles procurando questionar a "morte por decreto" da metafísica: Volker Gerhardt (cf., p. ex., Gerhardt, V. Individualität. Das Element der Welt. München: C.H. Beck, 2000); Manfred Frank (cf., p. ex., Frank, M. Auswege aus dem Deutschen Idealismus. Frankfurt-am-Main: Suhrkamp, 2007); Reiner Wiehl (cf., p. ex., Wiehl, R. Metaphysik und Erfahrung. Philosophische Essays. Frankfurt-am-Main: Suhrkamp, 1996); Gunnar Hindrichs (cf. p. ex., Hindrichs, G. Das Absolute und das Subjekt. Untersuchungen zum Verhältnis von Metaphysik und Nachmetaphysik. Frankfurt-am-Main: Vittorio Klostermann, 2008); Richard Schaeffler (cf., p. ex., Schaeffler, R. Ontologie im nachmetaphysischen Zeitalter. Geschichte und neuer Gestalt einer Frage. Freiburg, München: Verlag Karl Alber, 2008); Christian Thies (cf., p. ex., Thies, C. Der Sinn der Sinnfrage. Metaphysische Reflexionen auf kantianischer Grundlage. Freiburg, München: Verlag Karl Alber, 2008). Este último, inclusive, menciona Dieter Henrich como um "preparador de terreno" para o retorno às questões metafísicas "em bases kantianas" justamente por ter enfrentado o argumento da morte da metafísica no momento em que ele se encontrava consolidado (depois dos anos 1960 e 70). Cf. Habermas, J. Nachmetaphysisches Denken, p. 168.

15. Idem, p. 273.

16. Idem, p. 277. Habermas se refere aí ao livro: Mccarthy, T. et alli. After Philosophy. End or Transformation? Boston: Massachusetts Institute of Technology, 1987. 
Como se vê, e este é um dos argumentos que de fato mais utiliza na polêmica com Henrich, Habermas procura apontar aí para aquela que seria a grande tendência da filosofia contemporânea, iniciada já no século XIX com Hegel, Marx e Nietzsche e radicalizada no XX com a teoria crítica, de um lado, e a virada linguísticoanalíitica de outro: desfeitas as ilusões de um acesso direto à verdade "em si", seja do mundo seja da subjetividade, ter-se-ia inviabilizado aquela atitude clássica do filósofo que, declarando-se independente das ciências particulares, acreditava poder refletir sobre o homem em geral, a vida em geral ou o mundo em geral sem levar em conta as condições concretas do presente. $\mathrm{E}$ a menção a Jaspers, por seu turno, faz lembrar as críticas de Adorno a Heidegger: embora pretendendo superar a metafísica, o provinciano Heidegger, isolado na floresta, postulava ainda uma necessidade ontológica do homem que o cosmopolita Adorno, antenado com os últimos resultados das pesquisas sociais, não aceitaria jamais. ${ }^{17}$

Henrich, contudo, parece preferir a trilha de Heidegger. E terá portanto, como ele, de justificar sua opção pelo universal: não o universal do "Ser enquanto tal", que o último acreditava poder atingir com o "des-encobrimento" da verdade, mas o universal daquela mesma subjetividade mental com que os modernos, talvez não tão ingênuos, simplesmente estabeleciam a sua desconfiança em relação ao primado dos sentidos. É esse, com efeito, o desafio mais geral com que Henrich se vê defrontado nas "Doze teses contra Habermas": contra a suposta evidência da "morte do sujeito" - também perpetrada, em grande medida, pelo serial killer Nietzsche (mais conhecido pela "morte de Deus") -, ele tem de mostrar tanto a possibilidade como a necessidade, face às próprias questões colocadas pelo mundo moderno, de seguir recorrendo a essa tão controvertida noção. Tratar-se-ia de mostrar, em outras palavras, que o homem moderno não apenas pode como precisa

17. A crítica de Adorno a Heidegger se expressa sobretudo em dois textos: no Jargão da autenticidade. Sobre a ideologia alemãa e na primeira parte da Dialética negativa ("Relação com a ontologia"). Ambos estão reunidos no volume 6 das obras completas editadas pela Suhrkamp: Adorno, T. Gesammelte Schriften, Bd. 6. Frankfurt-am-Main: Suhrkamp, 2003. 
recorrer à metafísica, em sua acepção moderna - essa que tem por base de sustentação o sujeito, não o mundo -, para pensar de maneira consistente a sua própria condição humana, sua relação com o outro, sua relação com o mundo e assim por diante. Ao ver de Henrich, portanto, é o próprio destino da filosofia que está em jogo quando se discute a morte da "metafísica".

Começando, pois, por relativizar a questão do nome "metafísica", ambíguo desde a origem e propenso a suscitar as mais grosseiras caricaturas, Henrich propõe nas "Doze teses" que tenhamos em mente as preocupações teóricas habitualmente associadas a esse, diz ele, "não-título". E que o façamos com a consciência - tão velha quanto a primeira Crítica kantiana, diga-se de passagem -, de que tais preocupações não se deixam resolver, à maneira dogmática, sob aquele "conceito forte de teoria" que, segundo Habermas, acompanharia todo e qualquer empreendimento metafísico. ${ }^{18}$ Já em Kant, com efeito, cuja tentativa de sistematizar a história desse campo filosófico seria "a mais rica de consequências", ${ }^{19}$ podemos encontrar uma reflexão bastante elaborada sobre o significado do tão temido termo: dividindo-a em, de um lado, investigação das condições de possibilidade do conhecimento e do agir, e, de outro, abertura para

18. Cf. Habermas, J. Nachmetaphysisches Denken, pp. 36-40 ("Aspekte metaphysischen Denkens"). Nesse texto, Habermas aponta quatro marcas fundamentais no pensamento metafísico: pensamento identitário, idealismo, conceito forte de teoria e filosofia da consciência (esta última como um elemento específico à metafísica pós-cartesiana). A esse respeito, conferir também o já citado livro de Henrich, D.: Zwischen Berwusstseinsphilosophie und Naturalismus, pp. 19 e ss. Já Dieter Henrich afirma que "a justificação da metafísica não decorre da pretensão a uma teoria infalível ou do direito de falar ex catedra em nome daqueles pensamentos últimos cuja força ela leva em conta". Henrich, D. "O que é metafísica?" O que é modernidade? Doze teses contra Jurgen Habermas". In: Cadernos de Filosofia Alemã, n 14, São Paulo, 2009, p. 87. Konzepte. Essays zur Philosophie in der Zeit, p. 14. Ao citar o texto "O que é metafísica? O que é modernidade? Doze teses contra Jürgen Habermas", referir-me-ei a ele como "Doze teses" e indicarei a página correspondente no texto publicado abaixo, acrescida da página no original alemão (Konzepte).

19. Henrich, D. "O que é metafísica?" O que é modernidade? Doze teses contra Jurgen Habermas”. In: Cadernos de Filosofia Alemã, no 14, p. 84. Konzepte. Essays zur Philosophie in der Zeit, p. 12. 
"temas e caminhos da reflexão" voltados a dotar de "completude" a nossa compreensão do mundo, Kant teria possibilitado enxergar a metafísica não mais como um saber daquilo que estivesse "além da física", mas sim como um saber daquilo que, "aquém da física", nos permitiria agir e pensar independentemente da física.

É claro que essa nossa capacidade (em vocabulário kantiano diríamos "faculdade") não pode ser "provada", no mesmo sentido em que, por exemplo, verificamos a existência de um objeto em nosso campo de visão. Mas a igual impossibilidade de refutá-la deveria bastar, conforme a célebre lição kantiana, para conter o ímpeto dos materialistas mais apressados - ansiosos por esquartejar outra vítima - e garantir, assim, a bipótese de sua operacionalidade enquanto base de nosso viver consciente (em vocabulário kantiano "razão pura prática"). Não porque assim o queiram os nossos, digamos, "caprichos contemplativos": para Kant, como para Henrich, é a razão, enquanto propriedade distintiva do homem, quem exige esse ponto de apoio na consciência, sem o qual não se poderia falar em liberdade - nem do agir nem do pensar. $\mathrm{E}$ isso não porque a razão constitua a nossa "essência suprafísica", eterna e atemporal: ao escrever a "História da razão pura", como fecho à "Doutrina transcendental do método" e à própria Crítica da razão pura, Kant deixou suficientemente claro o caráter histórico da razão ou, por outra, o modo histórico de sua reconstrução. Ao contrário do que pintam os seus caricaturistas, a razão não está pendurada nas nuvens, à espera do filósofo que saia da caverna para contemplála: firmemente enraizada na história das manifestações culturais humanas, ela se vem constituindo há pelo menos dois milênios e meio, e segue a constituir-se. Mais simplificador do que projetá-la num céu estrelado, metáfora perfeitamente perdoável por quem não tenha parti pris, é circunscrever a sua história a essas poucas décadas de despotismo da linguagem a que parece condenar-nos o grande gesto do linguistic turn.

Não à toa, é justamente ao questionamento dessa "virada", responsável por aquilo que Habermas denomina "mudança de paradigma", que Henrich dedica boa parte de seus esforços nas "Doze teses". Não se trata, naturalmente, de recusar valor às investigações teóricas resultantes dessa "reorientação da teoria funda- 
mental rumo à comunicação linguística", ${ }^{20}$ entre as quais "a teoria dos signos, em especial sua semântica (sua teoria dos significados", que Henrich estudou a fundo ${ }^{21}$ e que, segundo ele, aportou

novos meios para o aclaramento de velhas questões e tarefas teóricas da filosofia. Questiona-se apenas se esse impulso teórico pode ser interpretado como uma mudança histórica de paradigma, graças à qual a autoconsciência, até então manipulada numa posição teórica oculta, mas agora tendo de ser vista como infundada e questionável também enquanto forma de vida, poderia obter a sua redenção por meio da passagem à comunidade comunicativa de um mundo da vida comum. ${ }^{22}$

É curioso, de fato, que Habermas aceite tão tranquilamente o "hábito" de "transpor à história da filosofia o conceito de paradigma, oriundo da história da ciência, e adotar uma divisão aproximativa das épocas com base em 'ser', 'consciência' e 'linguagem", ${ }^{23}$ sem estranhar que à primeira correspondam quase dois mil anos, à segunda trezentos e à terceira, de que ele próprio é ainda participante, apenas umas poucas décadas. Ora! Sem o mínimo distanciamento temporal, soa inverossímil, sobretudo em se tratando da filosofia, postular o fim de uma época histórica: embora desejando dissociar-se de certos "revolucionários epistemológicos" da filosofia, como Nietzsche e sobretudo Heidegger, Habermas se vale do mesmo anúncio messiânico para, ainda que de maneira retoricamente contida e numa direção supostamente inversa, fomentar o abandono daquela tradição filosófica que o criticismo kantiano,

20. Idem, p. 102; Idem, p. 29.

21. Cf., p. ex., Henrich, D. "Wohin die deutsche Philosophie?". In: Konzepte. Essays zur Philosophie in der Zeit, pp. 66-75. Como aponta o próprio Habermas, Henrich passou, antes de lançar-se à defesa da metafísica, por uma fase de, segundo ele, maior comedimento, na qual compreendia que "os verdadeiros filósofos (...) tiveram de portar-se de modo receptivo ou seja, adotar uma atitude de aprendizado em relação à filosofia analítica”. Habermas, J. Nachmetaphysisches Denken, p. 267.

22. Henrich, D. "O que é metafísica?" O que é modernidade? Doze teses contra Jurgen Habermas”. In: Cadernos de Filosofia Alemã, n 14, p. 103; Konzepte. Essays zur Philosophie in der Zeit, p. 30.

23. Habermas, J. Nachmetaphysisches Denken, p. 20. 
alicerçado na história da razão, pretendera blindar contra os ataques tanto do ceticismo como da superstição e do misticismo.

É certo que Habermas também pretende, prima facie, salvaguardar o núcleo racional do Iluminismo dessa cruzada irracionalista que, alimentada pela vaga nietzschiana, teria acabado por engolir até mesmo a primeira geração da sua Escola de Frankfurt. ${ }^{24}$ Segundo Henrich, porém, a hipótese de uma ruptura paradigmática em relação à noção moderna de subjetividade - leia-se kantiofichtiana - implicaria necessariamente a ruína da razão e, com ela, daquilo a que Habermas costuma denominar "projeto moderno". ${ }^{25}$ Deste ponto de vista, Heidegger e os pós-modernistas seriam bem mais coerentes com o espírito da "revolução linguística" do que a filosofia comunicativa habermasiana, ${ }^{26}$ cuja noção de racionalidade, transferida integralmente da consciência para a intersubjetividade, acabaria por aproximá-lo perigosamente de uma posição cético-positivista ou, no contexto do debate ora em questão, do assim chamado "naturalismo". ${ }^{27}$

24. Refiro-me à conhecida crítica de Habermas à Dialética do esclarecimento, desenvolvida sobretudo em Habermas, J. Discurso filosófico da modernidade. Trad. de Luiz Repa e Rodnei Nascimento. São Paulo: Martins Fontes, 2002, pp. 169 e ss.

25. Basta lembrar a frase de abertura ao Discurso filosófico da modernidade: “Modernidade - um projeto inacabado' era o título de um discurso que pronunciei em setembro de 1980, quando recebi o Prêmio Adorno. Esse tema, controvertido e multifacetado, não mais me deixou." (Idem, p. 1) Vale salientar a circunstância, também enfatizada por Habermas, de Henrich ser, dentre os defensores modernos da metafísica, um dos poucos a não criticar a modernidade, sendo antes um seu defensor. Nisto ele se distanciaria significativamente de nomes como Carl Schmitt, Leo Strauss e Arnold Gehlen (Habermas, J. Nachmetaphysisches Denken, p.20).

26. Cf. Henrich, D. "O que é metafísica?" O que é modernidade? Doze teses contra Jurgen Habermas”. In: Cadernos de Filosofia Alemã, no 14, p. 111; Konzepte. Essays zur Philosophie in der Zeit, p. 25.

27. Segundo Daniel Henrich, o "naturalismo mitigado" de Habermas se distingue do naturalismo forte, que seria próprio ao positivismo, porque, entre outras coisas, procura operar uma "união de Kant e Darwin, e não a redução de Kant a Darwin”. Henrich, Daniel. Zwischen Bewusstseinsphilosophie und Naturalismus. Zu den metaphysischen Implikationen der Diskursethik von Jürgen Habermas, p. 10. 
O que está realmente em jogo, portanto, é o quanto a noção de razão, enquanto núcleo desse amplo projeto cujo "potencial emancipatório" tanto Habermas como Henrich pretendem conservar, depende da noção de consciência ou subjetividade, tal como entendidas no contexto da filosofia kantiana e do idealismo alemão, para funcionar como, digamos, princípio condutor do progresso humano, seja este entendido como aprimoramento de nossas instituições sociais (preocupação dominante em Habermas), seja como base de sustentação para o amadurecimento "espiritual" do indivíduo humano (preocupação dominante em Henrich). Para Habermas, como se sabe, inexiste um tal vínculo: reservada a subjetividade para caracterizar o aspecto instrumental da razão - um aspecto necessário mas desprovido de elementos emancipatórios -, é na intersubjetividade que ele pretende, amparando-se na mencionada autoridade do linguistic turn, ancorar o aspecto comunicativo da razão, que abarcaria então o potencial emancipatório contido (mas irrealizado) na tradição iluminista.

Nesse quadro, torna-se fundamental compreender então o que Habermas entende por intersubjetividade, e por que a intersubjetividade é preferível à subjetividade no sentido de "fundamentar" a razão em seus aspectos genuinamente iluministas. Simplificando bastante o argumento, o que Habermas nos diz, quando explica ou justifica a mudança de paradigma, é que a linguagem se tornou o objeto preferencial da filosofia - em seu trabalho conjunto com as ciências sociais - por ser apreensível a partir da observação empírica, ensejando assim a constituição de disciplinas - como a teoria dos signos e a sua própria teoria do agir comunicativo - capazes de estudá-la com elevado grau de rigor. ${ }^{28} \mathrm{E}$ é a partir desse estudo da linguagem, entendida esta em seu sentido mais amplo (suas várias formas possíveis), que poderíamos formar uma compreensão adequada da intersubjetividade, ao passo que da subjetividade, se feita abstração da linguagem, só poderíamos formar vagas conjecturas e imagens, caindo então nas mais complicadas aporias. ${ }^{29}$

28. Cf., p. ex., Habermas, J. Nachmetaphysisches Denken, pp. 14 e ss.

29. Cf. idem, p. 18: “...a virada linguística colocou o filosofar sobre uma base metodológica mais segura e o livrou das aporias das teorias da consciência”. 
Ora! Se o que torna a intersubjetividade preferível à subjetividade, enquanto base da filosofia, é a sua maior cognoscibilidade do ponto de vista empírico, então começamos a entender uma das principais acusações de Henrich nas "Doze teses": ainda que a noção habermasiana de empiria, marcada tanto pelo alargamento do âmbito das ciências naturais como pela compreensão teóricocrítica das ciências sociais, seja bem mais elástica do que aquela que vigorava no positivismo, ${ }^{30}$ salta aos olhos a semelhança no modo como a filosofia se subordina ao ponto de vista científico. ${ }^{31}$ E com isso a eventual vantagem do "naturalismo", que o próprio Habermas por vezes assume, ${ }^{32}$ em relação ao positivismo tornase irrelevante: de certo modo, aquele é apenas uma versão mais "consciente" do último, já que a opção pela natureza se mostra como opção, e não como "verdade" (algo que, é claro, o "falibilismo" habermasiano não comportaria).

Habermas alega que a opção, no caso, não é uma mera arbitrariedade, como o seria uma crença subjetiva qualquer, mas sim o fruto de um processo histórico em que o naturalismo se teria firmado como "verdade" para a nossa época, o que segue à risca a velha

30. Cf.idem, p. 14 .

31. Cf. idem, p. 26: "Os critérios de validade segundo os quais o saudável entendimento humano poderia hoje iluminar-se por meio da filosofia não estão mais à disposição da própria filosofia. Ela tem de operar sob condições de racionalidade não escolhidas por ela mesma. Por isso ela não pode, mesmo na função de intérprete, reclamar para si, perante a ciência, a moral e a arte, um acesso privilegiado a intuições essenciais, e dispõe apenas de um saber falível."

32. Cf. p. ex., idem, p. 30. Segundo propõe Daniel Henrich, "a crítica de Jürgen Habermas à metafísica encontra expressão em uma estratégia naturalista de argumentação cujos traços se deixam seguir até os seus escritos de juventude". Henrich, Daniel. Zwischen Berwusstseinsphilosophie und Naturalismus. Zu den metaphysischen Implikationen der Diskursetbik von Jürgen Habermas, p. 9. Em seu livro, com efeito, Daniel Henrich se esforçará em demonstrar a importância do naturalismo, ainda que mitigado, como visto, sob a forma de um schwachen Naturalismus, para a posição de Habermas relativamente à metafísica, sendo particularmente marcantes, a esse respeito, as influências de Quine e sobretudo Mead. Cf. idem, pp. 61 e ss. ("Das darwinistische Modell der Einstellungsübernahme: Naturalismus statt Metaphysik") 
lição frankfurtiana de que a verdade é essencialmente histórica. ${ }^{33}$ Antes mesmo de nos perguntarmos se a afirmação "a verdade é histórica" é ela própria histórica, em lembrança ao bom e velho paradoxo do relativismo, vale notar por ora que, a favor ou contra o vento do progresso, o naturalismo constitui uma franca tomada de posição (Heidegger falaria aqui numa "decisão historial") ${ }^{34}$ relativamente ao que deve - e o que não deve - valer como objeto da reflexão filosófica. ${ }^{35} \mathrm{E}$ a subjetividade, como de resto a liberdade, o incondicionado, o cosmo etc, devem ficar de fora da lista porque não se prestam a uma análise empiricamente verificável ou falseável, ${ }^{36}$ conduzindo antes a tergiversações prolongadas e inúteis.

33. Cf. Horkheimer, M. "Teoria tradicional e teoria crítica”. In: ; Adorno, T. Textos escolbidos. (Coleção Os pensadores, vol. XIV.) São Paulo: Abril Cultural, 1982.

34. Pensando em termos heideggerianos, mas incorporando o próprio Heidegger à história da metafísica de que ele se pretendia um superador, poderíamos dizer que a virada linguística inaugura uma nova época dessa história, a linguagem ocupando o lugar do antigo sujeito e a intersubjetividade constituindo a nova determinação ôntica do ser. E Habermas seria uma espécie de Kant da nova era, já que nele essa "decisão metafísica" se expressa de maneira particularmente clara e autoconsciente.

35. Quanto à circunstância de o naturalismo constituir uma visão monista do mundo, por oposição ao dualismo de matriz platônica, lembra-nos Henrich: "(...) pode-se chamar também a esse naturalismo, com todo direito, uma metafísica. Pois a metafísica, enquanto tal, não é necessariamente antinaturalista, como bem o mostram os exemplos de Aristóteles, Spinoza e Nietzsche. Ela é, de todo modo, algo diverso de uma teoria científica. Aquele naturalismo, porém, que se vincula de fato aos resultados da física, afirma a opinião, em geral solidária com a teoria física, de que ele seria uma descrição exata da realidade, e não um instrumento da dominação teórica do conhecimento por experiência. Mas ele é, em seu resultado, uma extrapolação das disciplinas científicas, e, em sua estrutura, uma síntese das mesmas - e, enquanto tal, não pode ser ele mesmo o resultado de pesquisas. Com isso, ele corresponde amplamente ao conceito kantiano de uma metafísica da completude. E corresponde também à compreensão moderna de metafísica, na medida em que pretende ser uma compreensão última sobre o conjunto dos modos da experiência e formas discursivas diferentes entre si." Henrich, D.“O que é metafísica?” O que é modernidade? Doze teses contra Jurgen Habermas”. In: Cadernos de Filosofia Alemãa, no 14, p. 96-7; __. Konzepte. Essays zur Philosophie in der Zeit, p. 24.

36. Como se sabe, o princípio do falibilismo, importado de Popper, não opera com comprovações ou verificações. O que define o caráter científico de uma 
Em relação a tais assuntos, portanto, o filósofo deveria permanecer indiferente: dada a pluralidade de visões de mundo, concepções de bem e de vida, que proliferam nas sociedades modernas, cabe a cada um, individual ou coletivamente (no interior de uma religião, por exemplo), ${ }^{37}$ pensar o que quiser sobre eles, ou então abster-se de pensar. Ou seja: exatamente aquilo que pregava o "indiferentismo" do século XVIII, duramente combatido por Kant - "que tinha de divulgar sua obra numa época não tão embevecida com as hiperteorias metafísicas, mas antes marcada pela ironia e o escárnio em relação à metafísica" 38 - e oportunamente lembrado por Henrich nas "Doze teses":

Contra tal opinião [do indiferentismo], a veemente objeção de Kant, tão enraizada quanto possível nas conviç̧ões fundamentais de que brotou sua filosofia, diz o seguinte: 'Por mais que aqueles pretensos indiferentistas pretendam tornar-se irreconhecíveis também por meio das mudanças na linguagem escolástica, eles recaem inevitavelmente, na medida em que simplesmente pensam algo em geral, nas afirmações metafísicas contras as quais dirigiam tanto desprezo. ${ }^{39}$

Segundo Henrich, a afirmação de Kant cai como uma luva para Habermas porque também este, procurando esconder-se nas

teoria é, na verdade, a possibilidade de ela ser refutada ou falseada, dando lugar a uma teoria mais bem sucedida na explicação de um determinado leque de problemas. Cf. Popper, K. A lógica da pesquisa cientifica. São Paulo: Cultrix/Edusp, 1975, pp. 28 e ss.

37. É curiosa a importância dada por Habermas à religião, em detrimento da filosofia, enquanto possível espaço para o tratamento dessas questões: "Destituída de suas funções formadoras de mundo, a religião continua a ser, observada de fora, insubstituível para um modo normalizador de lidar com aquilo que é extraordinário no dia-a-dia. Por isso também o pensamento pós-metafísico coexiste ainda com uma prática religiosa. (...) Enquanto a linguagem religiosa trouxer consigo conteúdos semânticos inspiradores, e mesmo indispensáveis, que escapam (por ora?) à força de expressão de uma linguagem filosófica e seguem à espera de uma tradução para discursos fundamentadores, a filosofia, mesmo em sua figura pós-metafísica, não poderá substituir ou desalojar a religião." Habermas, J. Nachmetaphysisches Denken, p. 60.

38. Henrich, D. "O que é metafísica?" O que é modernidade? Doze teses contra Jurgen Habermas”. In: Cadernos de Filosofia Alemã, no 14, p. 88; Konzepte. Essays zur Philosophie in der Zeit, p. 15.

39. Idem, ibidem. A citação de Kant foi extraída do prefácio à primeira edição da Crítica da razão pura (KrV, A X). 
"mudanças da linguagem" (!) de nosso tempo, acaba por recair na metafísica na simples medida em que "pensa algo": conforme sugerido há pouco, escolher a intersubjetividade como princípio supremo da filosofia implica, mesmo tendo por base pesquisas empíricas de amplo respaldo na comunidade científica (como as de Piaget e Mead), e mesmo admitindo explicitamente a possibilidade de tais teorias virem a ser falseadas por teorias posteriores, uma decisão teórica com consequências metafísicas. ${ }^{40}$ Passa-se, por exemplo, a ver o homem como um ser essencialmente intersubjetivo, constituindo a subjetividade um fenômeno secundário, derivado e analisado a partir daquela. E isso de um modo tão extremo que, no limite, o adversário teórico poderia ser desqualificado com base numa espécie de diagnóstico clínico: assim como Nietzsche zombava dos homens gregários por não serem suficientemente profundos (à diferença do filósofo solitário, muito mais próximo do "ser"), o "filósofo tradicional" (uma caricatura tipicamente nietzschiana, diga-se de passagem) pode ser visto como alguém que, por problemas, digamos, na relação com a mãe, desviou-se do padrão saudável de sociabilidade, fechou-se em si mesmo e, quiçá isolado na floresta, passou a alimentar-se da ilusão de que seus pensamentos solitários seriam mais do que meras expressões de sua patologia. ${ }^{41}$ Enquanto isso, o filósofo comunicativo, urbano e

40. Também Volker Gerhardt, num artigo em que comenta a polêmica HabermasHenrich, afirma que, mesmo concedendo razão a Habermas nas críticas que faz à concepção henrichiana de subjetividade, isso nada aportaria contra a metafísica em si. "Pelo contrário: já com a sua crítica ao dualismo e ao princípio da subjetividade move-se Habermas no âmbito da metafísica. Mesmo que sua a reconstrução linguístico-pragmática da autoconsciência fosse bem sucedi$\mathrm{da}$, permaneceriam atuais as perguntas acerca do estatuto e do alcance dessa teoria. Além disso, com a reconstrução não seriam eliminadas as funções elementares da autoconsciência humana no contexto do agir e do saber. Nós seguiríamos tendo de contar com a circunstância de que ela vale para todos nós." Gerhardt, V. "Metaphysik und ihre Kritik. Zur Metaphysikdebatte zwischen Jürgen Habermas und Dieter Henrich.” In: Forschung. Bd. 42, Hft. 1, jan-mar.1988, p. 60.

41. A estratégia do deboche sociologicamente embasado é típica da tradição frankfurtiana, tendo sido bastante explorada por Adorno no Jargão da autenticidade. Ainda que mais contido, Habermas faz algo similar com Henrich e 
saudável, aproxima-se da "verdade" à medida que se mostra capaz de compartilhar o trabalho reflexivo com seus pares, sempre a partir de pesquisas empíricas, e assim estabelecer "diagnósticos" cujo sucesso se deixará medir pela recepção junto à comunidade científica. ${ }^{42}$

Casos clínicos à parte, o argumento de fundo, empregado tanto por Kant como por Henrich - e a fortiori por Nietzsche -, aponta para a circunstância de a visão de mundo do filósofo refletirse inevitavelmente em seu pensamento: se há algo de ingênuo na "tradição", esse algo é a crença na neutralidade do próprio discurso, habitualmente importada da ciência por filósofos sem nenhuma "paciência do conceito". Ora! Pois não foi justamente para escapar dessa atitude ingênua que a modernidade inventou o sujeito? $\mathrm{O}$ cogito cartesiano não resultou de uma radicalização da dúvida? A coisa em si kantiana não tem por fim precaver-nos contra a tentação de falar em nome das coisas mesmas?... Fora do reino das caricaturas, o "sujeitão" moderno nada mais é do que essa consciência do elemento subjetivo necessariamente presente em todo discurso, segundo nos ensinou o processo bistórico efetivo da reflexáo filosófica - um processo tão palpável quanto a linguagem cotidiana contemporânea, desde que nos disponhamos a levar Platão, Agostinho e Descartes pelo menos tão a sério quanto, digamos, as "autodescrições" dos indivíduos comuns sondados hoje pelas pesquisas estatísticas de opinião. ${ }^{43}$

Desse ponto de vista, é preciso refletir com mais cuidado sobre a posição ocupada pelo conceito de sujeito na filosofia mo-

os defensores da metafísica, por exemplo em Habermas, J. Nachmetaphysisches Denken, pp. 270-1.

42. Para as "ciências experimentais modernas e a moral que se tornou autônoma", confiantes apenas na "racionalidade de seu próprio procedimento", "o caráter racional dos conteúdos se volatiliza na validade dos resultados", de modo que "passa a valer como racional não mais a ordem das coisas encontrada no próprio mundo, projetada pelo sujeito ou mesmo surgida do processo de formação do espírito, mas sim a solução de problemas que se consegue quando a realidade é manipulada de maneira correta”. Idem, pp. 42-3.

43. Para a crítica das "autodescrições”, cf. Henrich,D. "O que é metafísica?” O que é modernidade? Doze teses contra Jurgen Habermas", tese 3 ("Autodestruições"). In: Cadernos de Filosofia Alemã, no 14, p. 89-90; Philosophie in der Zeit, pp. 15-7. 
derna, em especial naqueles filósofos que acabaram por constituir o ápice das investigações em torno dele, a saber, Kant e Fichte. Quando este afirma, por exemplo, que "Eu = Eu", é preciso ter claro, em que pese a obviedade da lição, que "Eu" não corresponde aí àquilo que habitualmente designamos por essa palavra: trata-se antes de uma noção que permite apenas dar à fórmula lógica "A = A" um sentido efetivo, já que a noção de "Eu" diz respeito à percepção de algo como um foco de atividade vital que, de resto inexplicável, parece constituir para nós um "lugar" interior ${ }^{44} \mathrm{E}$ tanto nosso "pensamento" como nosso "discurso" $p a-$ recem emanar desse "lugar", independentemente de ele ter sido configurado nas relações intersubjetivas, estar inscrito no código genético ou ter sido concebido por Deus: por mais que a vida social prevaleça sobre a individual, como seria o caso em sociedades coletivistas (à parte a idealização hegeliana da eticidade grega perdida), há algo que identificamos como um "eu" e que é distinto do "nós", assim como do "tu" e do "ele". Mas o que Fichte pretende designar com o seu "Eu" do "Eu = Eu" não é esse "eu" propriamente dito: ele apenas parte dessa nossa percepção, de algo ativo produzindo movimento a partir de dentro, para propor um princípio supremo minimamente compreensível ali onde, de outro modo, ele teria simplesmente de dizer "X $=\mathrm{X}$ ". Há algo que "põe", há algo que "gera": o grau de indeterminação é tanto que soa bizarro, para dizer o mínimo, vincular essa reflexão à razão instrumental do indivíduo que só pensa nos próprios fins (em que pese o sucesso de público da bravata, sobretudo no caso da Dialética do esclarecimento).

Seja como for, a função do "Eu" ou do sujeito, nesse esquema, seria simplesmente a de marcar esse foco de movimento que

44. "[O princípio absolutamente primeiro, Eu=Eu] deve exprimir aquele estado-de-ação que não aparece nem pode aparecer entre as determinações empíricas de nossa consciência, mas que, muito pelo contrário, está no fundamento de toda consciência e é o único que a torna possível." Fichte, J.G.A Doutrina-da-ciência de 1794.In:__. A Doutrina-daciência de 1794 e outros escritos. Seleção e tradução de Rubens Rodrigues Torres Filho. São Paulo: Abril Cultural, 1984 (2a . edição), p. 83. Cf. tb. Henrich, D. Fluchtlinien. Philosophische Essays, pp. 136-8. 
percebemos como ativo em nós por oposição a tudo aquilo que percebemos passivamente como coisas cujo foco de movimento não está em nós, mas nelas mesmas - donde o "não-Eu" fichtiano e a "coisa em si" kantiana. E insistamos no grau de indeterminação: há algo que "põe" versus há algo que "é posto"; há um vetor que aponta "de dentro para fora", outro que aponta "de fora para dentro". ${ }^{5}$ Nada impede, por exemplo, que nos valhamos dessa oposição para, em um nível menos abstrato da reflexão, pensar a humanidade, de um lado, e a natureza, de outro: o "Eu", nesse caso, equivaleria a um grande "Nós" que, por meio de uma (nobilíssima) fiç̧ão teórica, seria tratado como um. E assim por diante: uma sociedade, um grupo minoritário, um movimento social, uma família... todos esses complexos coletivos podem ser pensados a partir dessa oposição $\mathrm{X}-\mathrm{Y}$, em que $\mathrm{X}$ diz respeito a "por em movimento" e Y a "sofrer a ação de um movimento".

A essa altura bem se poderia perguntar, impaciências do conceito à parte, qual a "utilidade" dessa oposição e, se ela for mesmo constitutiva do pensar filosófico (como quer Henrich), qual a "utilidade" da filosofia em geral (ou dessa filosofia teimosa que, ao contrário do que quer Habermas, recusa-se a "casar" com as ciências sociais). E à pergunta bem se poderia responder com outra pergunta, bem ao gosto dos "filósofos tradicionais": o que entendes tu por "útil”, meu caro Trasímaco? A qualquer resposta que este nos desse, Sócrates trataria então de demonstrar que a atribuição do valor de utilidade a determinadas coisas, em detrimento de outras, pressupõe uma atividade valorante que, sob pena de contradição

45. Com relação aos dois sentidos em que o 'eu' tem de ser tomado, diz Henrich: "Com a referência à expressão linguística para autoconsciência, o 'eu', pode-se marcar a dupla negação de identidade a ele ligada do seguinte modo: a primeira pessoa do singular distingue aquele que a utiliza, segundo a sua identidade, de dois modos: na medida em que o 'eu' se relaciona diretamente ao 'ele' ou ao 'tu', enquanto pessoa entre pessoas; mas na medida também em que o 'eu' se relaciona diretamente ao elemento neutro da terceira pessoa (dem 'es' der dritten Person neutrum), enquanto sujeito entre todas as entidades e estados de coisas conjuntamente tomados. Nós nos compreendemos originariamente como ao mesmo tempo um entre os outros e o Um em relação ao mundo inteiro." Henrich, D. Fluchtlinien. Philosophische Essays, p. 138. 
(performativa?), não pode ser igualada às próprias coisas valoradas: na relação de valoração, estas últimas funcionaram como "não-Eu" (ou como Y), enquanto o responsável (ou os responsáveis) pela valoração funcionaram como "Eu" (ou como X). Desse modo, todo ser humano que pretende emitir juízos de valor deveria admitir uma tal oposição e, assim, reconhecer a utilidade da filosofia. Somente aquele que lograsse viver em permanente suspensão do juízo, como propunham os antigos céticos - uma possibilidade altamente duvidosa -, estaria autorizado a rejeitá-la. ${ }^{46}$

Como esse, porém, não parece ser o caso de Habermas, caberia então verificar, como sugere Placidus Heider, até que ponto ele não opera implicitamente com essa oposição, ${ }^{47}$ repetindo assim os passos de seu filósofo preferido, Hegel, cuja intenção antidualista, anunciada com grande pompa, acabaria por enfraquecer-se sob a inesperada distinção Wirklichkeit-Realität. ${ }^{48}$ Que Habermas pretenda salvaguardar, além do descritivo, também o elemento normativo do projeto moderno, é sabidamente um dos principais motes de sua empreitada teórica, como ele próprio não se cansa de frisar:

Caso não deva permanecer arbitrário, esse conteúdo normativo precisa ser obtido e justificado a partir do potencial racional imanente à práxis cotidiana. $\mathrm{O}$ conceito de razão comunicativa, introduzido de maneira provisória e que aponta para além da razão centrada no

46. Cf. Henrich, D. "O que é metafísica?” O que é modernidade? Doze teses contra Jurgen Habermas”. In: Cadernos de Filosofia Alemã, no 14, p. 87-8; Konzepte. Essays zur Philosophie in der Zeit, pp. 14-5.

47. Ao contrário de Daniel Henrich, que tende a sublinhar os aspectos distintivos do naturalismo habermasiano face à posição de Dieter Henrich, Placidus Heider procura apontar para convergências entre os dois autores, sobretudo no modo como compreendem e defendem a racionalidade. Cf. Heider, P. Jürgen Habermas und Dieter Henrich. Neue Perspektiven auf Identität und Wirklichkeit. Freiburg, München: Alber, 1999, pp. 101-3.

48. A metacrítica kantiana é aqui um tanto elementar: se realidade e razão deveriam coincidir, de modo a evitar-se o terrível monstro kantiano da cisão subjetividade-natureza, como admitir essa súbita entrada em cena de uma dualidade efetividade-realidade, segundo a qual apenas "uma parte" da realidade (a efetiva) é racional? 
sujeito, deve conduzir para fora dos paradoxos e dos nivelamentos de uma crítica auto-referencial da razão. ${ }^{49}$

Coerente com o princípio do "primado da prática", por ele advogado desde os textos de juventude, ${ }^{50}$ Habermas parece sugerir aí um vínculo forte entre um de seus conceitos teóricos primordiais - a razão comuncativa - e o propósito de "adquirir e justificar" o conteúdo normativo que seria próprio ao "discurso filosófico da modernidade", orientando assim a sua filosofia à possibilidade de pensar a sociedade moderna na dupla dimensão dos pontos de vista descritivo e normativo, de "facticidade e validade" ${ }^{51}$ De espírito aparentemente kantiano, visto operar com esse "duplo ponto de vista", a proposta tende a enredar-se em complicações, no entanto, justamente quando se mostra dominante o viés hegeliano da sua compreensão da modernidade: tendo de limitar ao máximo essa "dualidade" da oposição descritivo-normativo, sob pena, como sempre, de recair nos braços da "velha rainha", a explicação habermasiana do elemento normativo terá de vincular-se constitutivamente ao descritivo, i.e. à própria "realidade em movimento", para falar em termos hegelianos. Em outras palavras, ele terá de fazer brotar do próprio real, na forma de tendências que se deixariam ler na interpretação reconstrutiva dos movimentos sociais, ${ }^{52}$ o tal conteúdo normativo cuja finalidade, por seu turno, seria dar regras e critérios a esse mesmo real.

49. Habermas, J. O discurso filosófico da modernidade, p. 473.

50. É essa, como se sabe, a perspectiva dominante em Conhecimento e interesse, de 1968. Cf. Habermas, J. Erkenntnis und Interesse. Frankfurt-am-Main: Suhrkamp, 2007.

51. Refiro-me, naturalmente, ao título daquela que é, certamente, a obra mais importante de Habermas nos anos 1990, e que opera justamente a partir dessa dupla perspectiva: Habermas, J. Faktizität und Geltung. Beiträge zur Diskurstheorie des Rechts und des demokratischen Rechtsstaats. Frankfurt-amMain: Suhrkamp, 1992.

52. Acerca do significado que tem a reconstrução no modo como Habermas entende a filosofia, cf. Repa, L. A transformação da filosofia em Jürgen Habermas. Os papéis de reconstrução, interpretação e crítica. São Paulo: Singular/Esfera Pública, 2008, pp. 135 e ss. 
E assim acabaríamos por, agora sim, recair naquele círculo vicioso que, talvez irrelevante do ponto vista das (genuínas) intenções emancipatórias, nos impediria contudo, segundo a mais elementar metacrítica kantiana, de estabelecer uma fundamentação filosófica - tanto faz se "fraca" ou "forte", se "semi-" ou "pleni-" transcendental - das normas morais e jurídicas: conforme Kant, do fato de algo ser assim ou assado não se segue que algo deva ser assim ou assado; nem do fato de algo apontar para isso ou aquilo (uma tendência) se segue que algo deva ser isso ou aquilo. A menos que se introduza, como fez Hegel, uma distinção ontológica violenta entre dois "tipos" de real - um que apenas é (Realität), outro que é porque deve ser (Wiklichkeit) -, ficaremos de mãos amarradas frente à efetividade do mundo ou, que seja, dos movimentos sociais. Nos anos 1930, isso significaria assistir tranquilamente às manifestações da juventude nazista e, se possível, reconstruir a sua lógica interna de modo a deduzir, como tendências inscritas no real, o conteúdo normativo a ser seguido por todos. De certo modo, era justamente isso o que Heidegger andava fazendo na época. ${ }^{53}$

Se não queremos, porém, associar a esse obscurantismo filosófico a empreitada habermasiana, cujo fim é levar adiante os ideais iluministas que esse mesmo Heidegger pretendia sepultar, então devemos identificar os elementos positivos com que Habermas, ao arrepio de suas próprias declarações de intenção,

53. Nas preleções sobre Nietzsche dos anos 1936 a 40, reunidas no primeiro volume de seu Nietzsche, são muitas as passagens de tom profético em que Heidegger se refere, a partir das tendências que observa como próprias da época, o "grande acontecimento" que estava por vir, a "grande decisão" com que o povo alemão tinha de defrontar-se etc. Tome-se como exemplo a seguinte: "Essa semblância permanece enquanto ninguém tiver ainda conseguido pressentir e, antes de tudo, enquanto ninguém tiver ainda avaliar em sua amplitude que, apesar da preponderância da técnica e da "mobilização" universalmente tecnicizada do globo terrestre, ou seja, a partir de um predomínio muito determinado da natureza capturada, irrompe um poder do ser totalmente diferente: a história que não é mais representada pela historiografia como seu objeto." Heidegger, M. Nietzsche, vol. I, Trad. de Marco Antônio Casanova. Rio de Janeiro: Forense, 2007, p. 351. Cf. tb., p. ex., idem, p. 418 e idem, pp. 468-9 
acaba por preencher de conteúdo o "lado racional" do mundo ou, nos termos há pouco sugeridos, o lado "subjetivo" da oposição "Eu- não-Eu". E esse lado, na verdade, acabou de no-lo mostrar o próprio Habermas, com a idéia de uma razão comunicativa que, por oposição à instrumental, ocupa um lugar lógico idêntico ao da razão prática kantiana, relativamente à teórica: onde uma opera mecanicamente com com causas e efeitos, não importando os meios para atingir os fins visados, a outra opera segundo uma lógica própria na qual o ser humano não é nunca tratado como meio, seja porque é visto como membro de uma comunidade de seres racionais, seja porque é visto como participante da comunicação cuja situação tem de ser isonômica em relação aos demais.

Se não interpretarmos literalmente as metáforas kantianas (reino dos fins, mundo inteligível etc), então o que temos, num caso como no outro, são simplesmente dois pontos de vista a partir dos quais podemos considerar-nos ora como meios, inseridos numa série de causas e efeitos - ou como peças na engrenagem dos sistemas dinheiro e poder, para falar nos termos de Habermas -, ora como fins em si mesmos - ou como membros de uma comunidade racional comunicativa com direito à igualdade de participação nos processos argumentativos. E que este último ponto de vista tenha um caráter assumidamente "ideal", i.e. que funcione como idéia reguladora em relação ao "mundo da vida" e o desenvolvimento das instituições, é algo perfeitamente aceitável do ponto de vista daquela oposição X-Y que, segundo a leitura kantio-henrichiana, é constitutiva de todo filosofar.

Nesse ponto, aliás, é emblemática a atitude de Karl-Otto Apel, conhecido por ser co-fundador da ética do discurso ao lado de Habermas: para ele, o modelo teórico que serve de base à fundamentação filosófica, em regime contemporâneo, é o modelo kantiano, funcionando a "comunidade ideal de fala", em alguns momentos abraçada pelo próprio Habermas, ${ }^{54}$ como o fundamen-

54. Habermas não fala tanto em "comunidade", mas em "situação ideal de fala". Segundo nos mostra Luiz Repa, Habermas adotou esse conceito ostensivamente, com a função de uma idéia reguladora, até o momento em que, aceitando a crítica de Wellmer - segundo quem o "ideal" tem de ser dado 
to transcendental da nova ética..$^{55}$ Embora também se pretenda "pós-metafísico", por crer que teria escapado à filosofia do sujeito, ${ }^{56}$ Apel não resistiria por muito tempo ao ataque henrichiano, sendo fácil vincular esse caráter transcendental da comunidade ideal àquela ampla corrente da filosofia contemporânea que, conforme sugerimos há pouco, poderia ser descrita como uma metafísica da intersubjetividade - uma corrente que, segundo Henrich, teria em Rousseau uma espécie de precursor, devido à sua visão negativa do indíviduo, e se firmaria a partir de então com os

diversos esforços intelectuais e movimentos políticos reformistas visando reconquistar, para os indivíduos depravados pela desunião, uma comunidade acolhedora ou uma vida política em que o 'sujeito' possa libertar-se e tornar-se 'cidadão' ou 'camarada. ${ }^{57}$

A esses esforços estariam vinculados, num primeiro momento, os nomes de Jacobi, "segundo o qual cada 'eu' teria seu complemento num 'tu”, e do jovem Hölderlin, cuja Vereinigungsphilosophie teria intuito similar. Em seguida viriam o Fichte da "filosofia social do reconhecimento", Feuerbach e Marx, com a "antropologia do homem como ser essencialmente social”, e mais tarde

a teoria da intersubjetividade de Husserl, o conceito lukácsiano de consciência de classe e o tratado de Martin Buber sobre a originariedade da dimensão que institui, entre 'eu' e 'tu', a abertura de um para o outro. ${ }^{58}$

concretamente, na própria situação real de fala -, atenuou a noção e deixou de tê-la como um elemento central de sua "fundamentação" da ética do discurso. Repa, L. A transformação da fllosofia em Jürgen Habermas, pp. 96 e ss.

55. Cf. Apel, K-O. Diskurs und Verantwortung. Das Problem des Übergangs zur postkonventionellen Moral. Frankfurt-am-Main: Suhrkamp, 1988, pp. 50 e ss.

56. Cf. Apel, K-O. "Disursethik als Verantwortungsethik. Eine postmetaphysische Transformation der Ethik Kants”. In: Schönrich, G.; Kato, Y. (orgs.) Kant in der Diskussion der Moderne. Frankfurt-am-Main: Suhrkamp, 1997, pp. 24 e ss.

57. Henrich, D. "O que é metafísica?" O que é modernidade? Doze teses contra Jurgen Habermas". In: Cadernos de Filosofia Alemã, no 14, p. 110; Konzepte. Essays zur Philosophie in der Zeit, p. 37.

58. Idem, ibidem. 
Depois seria a vez de Heidegger, “determinando esse 'entre' como linguagem", e em seguida a onda do pragmatismo americano, cujas semelhanças com a "filosofia do homem como ser linguístico" seriam logo notadas e dariam origem à "doutrina da originariedade dos jogos de linguagem, concebida em inglês por Wittgenstein". ${ }^{59} \mathrm{E}$ logo, como se pode imaginar, seria a vez de Apel e Habermas com a ética do discurso, a refletir em nova chave - cujos elementos kantianos, há pouco sugeridos, Henrich não parece todavia levar suficientemente em conta ${ }^{60}$ - essa mesma tendência geral a pensar o mundo a partir não mais da subjetividade, mas agora da intersujetividade ou da comunicação. ${ }^{61}$

Descartada por ora a hipótese de um movimento dialético da filosofia contemporânea cujo ponto de culminância fosse a filosofia de Habermas, o que parece desenhar-se nessa perspectiva é antes a convivência - em regime de concorrência - de dois pressupostos filosóficos distintos, um remontando a Rousseau-Hegel-Marx, o outro a Kant-Fichte: de um lado as filosofias da intersubjetivdade, de outro as da subjetividade. Com a importante diferença de que aquelas, ainda nas ilusões da "juventude", acreditam representar a superação de todo o passado filosófico, ao passo que as últimas, para sobreviver, não têm outra opção senão admitir sua filiação ao velho vício do "amor à sabedoria". É bem verdade que alguns dos "intersubjetivistas", menos radicais, procuraram vincular os seus

59. Idem, ibidem.

60. No texto "Agir comunicativo e razão destranscendentalizada", Habermas acolhe as idéias kantianas da razão em sua filosofia pós-metafísica - ou no horizonte da "razão destranscendentalizada" - num sentido não muito distante do sugerido por Henrich. Esse é um texto que permitiria pensar em Habermas não como um filósofo pós-metafísico, mas como um metafísico pós-kantiano - assim como o próprio Henrich. Cf. Habermas, J. Entre naturalismo e religião. Estudos filosóficos. Rio de Janeiro: Tempo Brasileiro, 2007, pp. 36-7.

61. O título da nona tese de Henrich sintetiza o modo como ele questiona essa substituição de "paradigmas": "Comunicação em vez de subjetividade?" (Kommunikation statt Subjektivität?) Henrich, D. "O que é metafísica?" O que é modernidade? Doze teses contra Jurgen Habermas". In: Cadernos de Filosofia Alemã, no 14, p. 103; . Konzepte. Essays zur Philosophie in der Zeit, p. 34. 
esforços pensantes aos esforços da tradição, marcando sua diferença menos pela "novidade" do que pelo modo novo de enfrentar as velhas indagações: sem falar no próprio Hegel, cuja grandeza filosófica (no sentido pleno do termo) é indiscutível, temos em Heidegger - sobretudo em Ser e tempo - o grande exemplo recente, constituindo a "analítica do Dasein" um projeto análogo à analítica kantiana no qual o "ser-no-mundo", também dito "ser-como-outro", ocupa o lugar que era antes do sujeito transcendental.

Sabe-se que o próprio Heidegger rejeitaria posteriormente a sua "analítica", por julgá-la ainda "metafísica". ${ }^{62}$ Mas o exemplo é oportuno, assim como aquele de Apel, justamente por isso: ele nos ajudar a ilustrar essa interpretação da cena filosófica contemporânea como um grande embate entre esses dois modelos metafísicos - o subjetivista e o intersubjetivista. E não nos importa por ora tomar posição: a grande vantagem dessa perspectiva é simplesmente evitar a ilusão de que a vitória do intersubjetivismo seria inexorável e, mais ainda, de que ela implicaria o fim da metafísica. Esta persiste, segundo procuramos mostrar, na simples medida em que persista a necessidade humana de valorar: quer interpretemos o polo ativo da relação valorante como "sujeito", quer como "comunidade de fala", em ambos os casos temos de distingui-lo do polo valorado, cujo nome, a rigor, também não importa (se coisa, objeto, mundo etc). Kantianamente falando, o que importa é garantir essa dualidade perspectiva, pois somente assim se evita que um dos polos acabe por engolir o outro, resultando ou num idealismo desvairado que faz tábula rasa da sensibilidade, ou num realismo hipertrofiado que elimina a possibilidade da moral.

Pois é isso o que está verdadeiramente em jogo, como vimos, quando se defende a metafísica da modernidade: se Habermas tem razão no que diz respeito ao primado da prática sobre a teoria como um "motivo do pensamento moderno", Henrich parece ter

62. Em termos heideggerianos: em vez de ir direto ao "Ser enquanto tal", como faria a poesia em sua fase pós-Kehre, Sein und Zeit teria tentado determinar o "Ser do ente enquanto tal", incorrendo assim na tendência encobridora típica da metafísica ocidental. Cf., a esse respeito, Nunes, B. Passagem para o poético. Filosofia e poesia em Heidegger. São Paulo: Ática, 1992, pp. 134 e ss. 
razão quando vincula a possibilidade desse primado à autonomia do ponto de vista (inter-?) subjetivo frente à abordagem descritiva das teorias de base empírica. Mesmo que se queira dar a maior voz possível às ciências sociais, seguiria sendo necessário distinguir o nível em que estas atuam, propondo descrições da subjetividade adequadas ao contexto histórico, daquele em que a reflexão filosófica, fazendo abstração do contexto para pensar a consciência em geral, "reconstrói" o conteúdo normativo da racionalidade humana a partir não do movimento limitado de umas poucas décadas, mas daquilo que se entende por razão desde que os primeiros filósofos se puseram a pensar o mundo, dois mil e quinhentos anos atrás. Sem uma perspectiva capaz de transcender o estreito campo da observação empírica, todo esse patrimônio vai por água abaixo, e o que ainda se ousar chamar de filosofia não será sequer uma pálida sombra daquilo que ela foi e ainda pode ser.

\section{Bibliografia}

ADORNO, T. Gesammelte Schriften. Bd. 6. Frankfurt-am-Main: Suhrkamp, 2003.

APEL, K-O. Diskurs und Verantwortung. Das Problem des Übergangs zur postkonventionellen Moral. Frankfurt-am-Main: Suhrkamp, 1988.

. "Disursethik als Verantwortungsethik. Eine postmetaphysische Transformation der Ethik Kants". In: KATO, Y.; SCHÖNRICH, G. (orgs.) Kant in der Diskussion der Moderne. Frankfurt-am-Main: Suhrkamp, 1997.

FICHTE, J.G. A Doutrina-da-ciência de 1794. In: A Doutrinada-ciência de 1794 e outros escritos. Seleção e tradução de Rubens Rodrigues Torres Filho. (Coleção Os Pensadores, vol. XXVI) São Paulo: Abril Cultural, 1984.

FRANK, M. Auswege aus dem Deutschen Idealismus. Frankfurt-am-Main: Suhrkamp, 2007.

GERHARDT, V. "Metaphysik und ihre Kritik. Zur Metaphysikdebatte zwischen Jürgen Habermas und Dieter Henrich.” In: Zeitschrift für philosophische Forschung, Bd. 42, Hft. 1, jan-mar.1988.

. Individualität. Das Element der Welt. München: C.H. Beck, 2000. 
HABERMAS, J.; HENRICH, D. Zwei Reden. Aus Anlass des HegelPreises. Frankfurt-am-Main: Suhrkamp, 1974.

. Nachmetaphysisches Denken. Frankfurt-am-Main: Suhrkamp, 1988.

Faktizität und Geltung. Beiträge zur Diskurstheorie des Rechts und des demokratischen Rechtsstaats. Frankfurt-am-Main: Suhrkamp, 1992.

Discurso filosófico da modernidade. Trad. de Luiz Repa e Rodnei Nascimento. São Paulo: Martins Fontes, 2002.

Pensamento pós-metafísico. Trad. de Flávio B. Siebeneichler. Rio de Janeiro: Tempo Brasileiro, 2002 (2a . ed.).

. Pensamento pós-metafísico. Trad. de Lumir Nahodil. Coimbra: Almedina, 2004.

Entre naturalismo e religião. Estudos filosóficos. Rio de Janeiro: Tempo Brasileiro, 2007.

. Erkenntnis und Interesse. Frankfurt-am-Main: Suhrkamp, 2007.

HEIDEGGER, M. Nietzsche. vol. I. Trad. de Marco Antônio Casanova. Rio de Janeiro: Forense, 2007.

HEIDER, P. Jürgen Habermas und Dieter Henrich. Neue Perspektiven auf Identität und Wirklichkeit. Freiburg, München: Alber, 1999.

HENRICH, Daniel. Zwischen Berwusstseinsphilosophie und Naturalismus. $\mathrm{Zu}$ den metaphysischen Implikationen der Diskursethik von Jürgen Habermas. Bielefeld: Transcript Verlag, 2007.

HENRICH, Dieter. Fluchtlinien. Philosophische Essays. Frankfurt-amMain: Suhrkamp, 1982.

. Konzepte. Essays zur Philosophie in der Zeit. Frankfurt-am-Main: Suhrkamp, 1988.

HINDRICHS, G. Das Absolute und das Subjekt. Untersuchungen zum Verhältnis von Metaphysik und Nachmetaphysik. Frankfurt-am-Main: Vittorio Klostermann, 2008.

HORKHEIMER, M. "Teoria tradicional e teoria crítica". In: e ADORNO, T. Textos escolbidos. Seleção e tradução de Zelijko Loparic, Andréia Loparic e Edgar Malagodi (Coleção Os pensadores, vol. XIV) São Paulo: Abril Cultural, 1982.

KANT, I. Kritik der reinen Vernunft. In: _. Kants gesammelte Schriften. Herausgegeben von der Königlich Preussischen Akademie der Wissenschaft. Vol. I. Berlim: W. de Gruyter, 1900. 
MARTINS, A. M. “Apresentação". In: HABERMAS, J. Pensamento pósmetafísico. Coimbra: Almedina, 2004.

McCARTHY, T. et alli. After Philosophy. End or Transformation? Boston: Massachusetts Institute of Technology, 1987.

NUNES, B. Passagem para o poético. Filosofia e poesia em Heidegger. São Paulo: Ática, 1992.

POPPER, K. A lógica da pesquisa científica. São Paulo: Cultrix/Edusp, 1975.

REPA, L. A transformação da filosofia em Jürgen Habermas. Os papéis de reconstrução, interpretação e crítica. São Paulo: Singular/Esfera Pública, 2008.

SCHAEFFLER, R. Ontologie im nachmetaphysischen Zeitalter. Geschichte und neuer Gestalt einer Frage. Freiburg, München: Verlag Karl Alber, 2008.

THIES, C. Der Sinn der Sinnfrage. Metaphysische Reflexionen aufkantianischer Grundlage. Freiburg, München: Verlag Karl Alber, 2008.

WIEHL, R. Metaphysik und Erfahrung. Philosophische Essays. Frankfurtam-Main: Suhrkamp, 1996. 